\title{
Structural Behavior of Thin-Walled Concrete-Filled Steel Tube Used in Cable Tunnel: An Experimental and Numerical Investigation
}

\author{
Hetao Hou, ${ }^{1}$ Su Ma, ${ }^{1}$ Bing Qu, ${ }^{1,2}$ Yanhong Liang, ${ }^{1}$ Yanjun Jin, ${ }^{3}$ \\ Wencan Zhu, ${ }^{1}$ and Lei Chen ${ }^{1}$ \\ ${ }^{1}$ School of Civil Engineering, Shandong University, Jinan 250061, China \\ ${ }^{2}$ Department of Civil and Environmental Engineering, California Polytechnic State University, San Luis Obispo, CA 93407, USA \\ ${ }^{3}$ Department of Building Engineering, Mianyang Vocational and Technical College, Mianyang 621000, China \\ Correspondence should be addressed to Bing Qu; bqu@calpoly.edu
}

Received 26 April 2015; Revised 9 June 2015; Accepted 10 June 2015

Academic Editor: Robert Cerný

Copyright (C) 2015 Hetao Hou et al. This is an open access article distributed under the Creative Commons Attribution License, which permits unrestricted use, distribution, and reproduction in any medium, provided the original work is properly cited.

\begin{abstract}
One steel grid and five thin-walled concrete-filled steel tubes (CTST) used as the supports of tunnel were tested in site for investigating the mechanical behavior. The mechanical influences of thickness, node form, and concrete on CTST were gained and compared with the impacts on steel grid. It is indicated that high antideformation capacity of CTST improved the stability of surrounding rock in short time. The cementitious grouted sleeve connection exhibited superior flexibility when CTST was erected and built. Although the deformation of rock and soil in the tunnel was increasing, good compression resistance was observed by CTST with the new connection type. It was also seen that vault, tube foot, and connections were with larger absolute strain values. The finite element analysis (FEA) was carried out using ABAQUS program. The results were validated by comparison with experimental results. The FE model could be referred by similar projects.
\end{abstract}

\section{Introduction}

Although steel grid and steel arch are common used structures for tunnel support, they are not good enough for large deformation control of soft rock. As a new structure, concrete-filled steel tubes (CFST) with high bearing capacity and good plasticity have a broad application prospect [13]. Under compressive loading, the local buckling resistance of the steel tube could be effectively enhanced by the filled concrete. At the same time, the strength, plasticity, and toughness of the concrete can also be boosted [4]. Li et al. [5] pointed out that deformation of surrounding rock could be effectively reduced by CFST for roadway supporting. However, the cost of CFST has to be reduced.

Compared with ordinary CFST, less steel and welding work are needed for CTST because of the thin wall. Previous research mainly focused on the experimental behaviour of CTST in the laboratory [6-8]. Despite low cost, few studies are conducted in site to test the influences of wall thickness and mechanical properties.

In this study, tests have been done in a cable tunnel in Jinan while an FE analysis by ABAQUS program is conducted to do further research on the application of CTST in tunnel.

\section{Test program}

2.1. Project Background of Cable Tunnel. The cable tunnel is located in Shunhua Road in Jinan. As the tunnel in strong weathered rock, it is $145 \mathrm{~m}$ long. The thickness of overlaying soil of the tunnel is about $6.7 \sim 8 \mathrm{~m}$. The maximum excavation height is $4.6 \mathrm{~m}$ while the largest excavation span is $6.75 \mathrm{~m}$. For presupport, advanced small pipes with $1.5 \mathrm{~m}$ longitudinal distance are supplemented. Then, C25 early-strength concrete is sprayed for primary support. Subsequently, steel grid or CTST is used to support the tunnel. At last, C30 waterproof 
TABLE 1: Parameters of CTST specimens.

\begin{tabular}{lccccc}
\hline Specimens & ST-1 & ST-2 & ST-3 & ST-4 & ST-5 \\
\hline$D(\mathrm{~mm})$ & 159 & 159 & 159 & 159 & 159 \\
$t(\mathrm{~mm})$ & 5.5 & 4.5 & 3.5 & 5.5 & 5.5 \\
Concrete & Filled in & Filled in & Filled in & Not filled in & Filled in \\
Connection & Cementitious & Cementitious & Cementitious & Cementitious & Ordinary sleeve \\
& grouted sleeve & grouted sleeve & grouted sleeve & grouted sleeve \\
\hline
\end{tabular}

Note: $D$ is the external diameter and $t$ is the thickness.

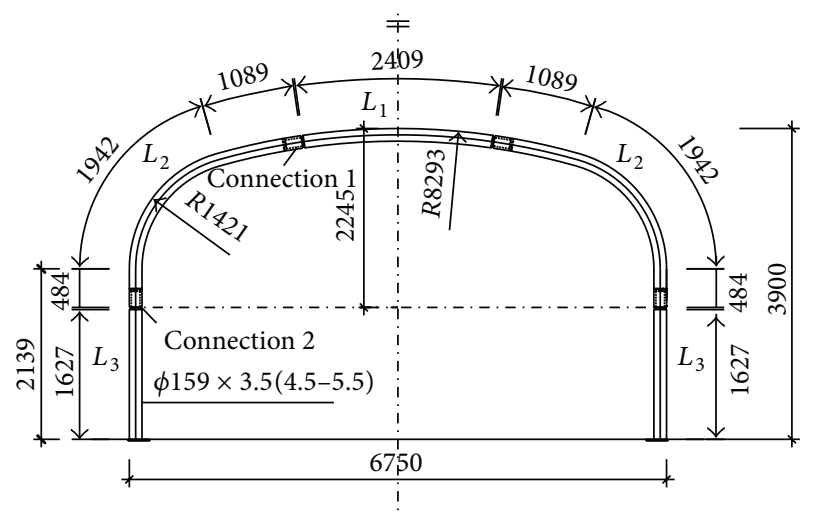

FIGURE 1: Size and segmentation of CTST support.

concrete with seepage resistance $P>8$ is adopted to improve the secondary lining.

2.2. Test Specimen. In the study, the steel tube is segmented for installation and transport. One end of segment is sealed while the other is opened. The segment is sealed by precast head pale once the concrete vibrating finished. Finally, the segments are spliced in site. According to the results of geological exploration, the counter-arch for the support is not set owing to the small effect of soil arch. The size and segmentation of CTST support are shown in Figure 1.

5 CTST specimens and 1 steel grid specimen are tested. The details of the test specimens are shown in Figure 2 and Table 1.

For the butt joint in the tunnel, a new cementitious grouted sleeve connection is designed and shown in Figure 3. Microexpansive cement mortar is grouted after the connection inserting. Comparing with the traditional connection, the new type with better yielding could satisfy the requirements of surrounding rock pressure. Besides, the new connection could reduce the welding works and avoid the tunnel excavation generated by butt joints.

According to "metallic materials at ambient temperature tensile test method" (GB/T228-2002), steel tube Q235B is used in the test. The yield strength of the steel tube is 255.3 MPa while the tensile strength is $330.7 \mathrm{MPa}$. The elastic modulus is $2.06 \times 10^{5} \mathrm{MPa}$ and Poisson's ratio is 0.30 . As what is shown in Figure 4, the steel tube is bent into the designed

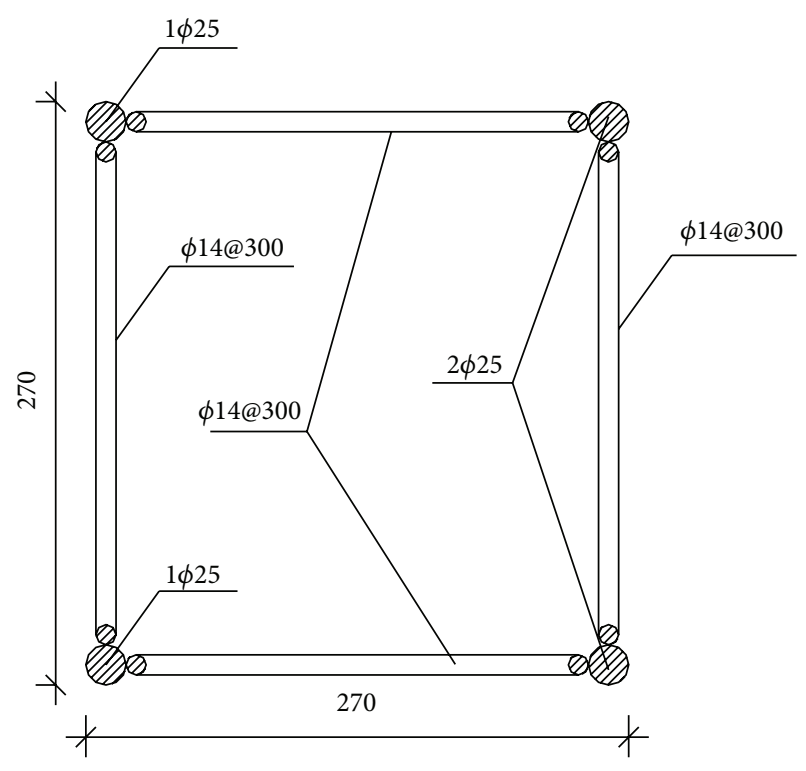

FIGURE 2: Steel grid section.

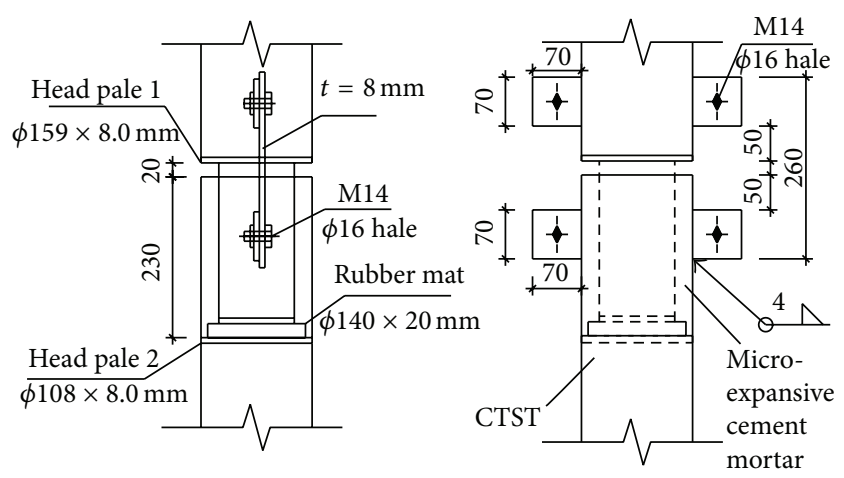

FIGURE 3: Details of cementitious grouted sleeve connection.

shape in the factory and then is stereotyped under cryogenic cooling.

The mix proportion of cement, sand, and gravel used in the concrete is $1: 1.51: 2.45$. The water cement ratio of the cement is 0.41 . The expansion agent ratio is $11 \%$. The water reducing agent ratio is $0.5 \%$. According to the relevant 


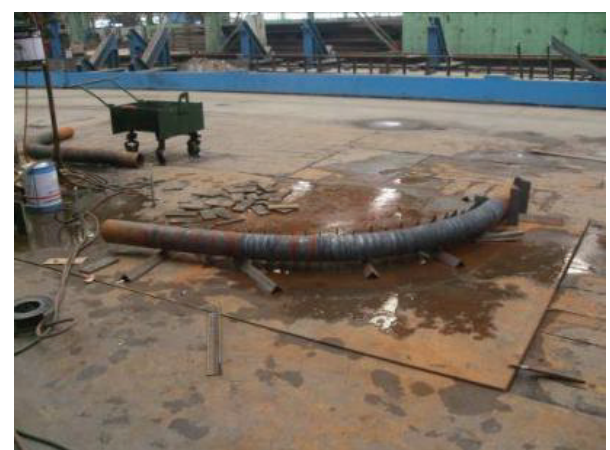

FIGURE 4: Manufacturing procedure of steel tube in factory.

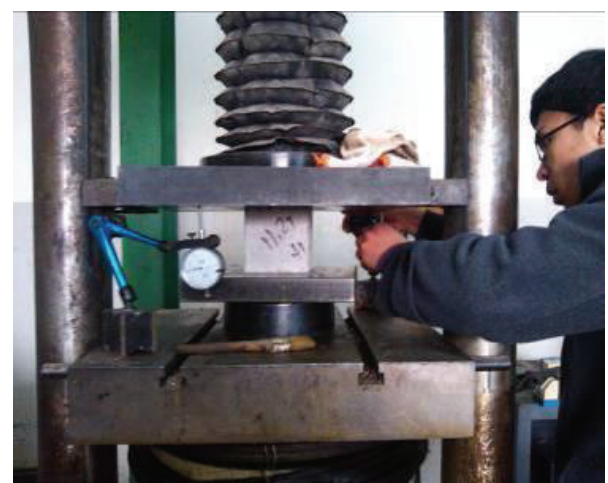

Figure 5: Material test of concrete.

TABLE 2: Compressive strength of concrete at different ages.

\begin{tabular}{lccc}
\hline Age & $3 \mathrm{~d}$ & $7 \mathrm{~d}$ & $28 \mathrm{~d}$ \\
\hline Compressive strength $(\mathrm{MPa})$ & 16.3 & 24.8 & 45.5 \\
\hline
\end{tabular}

Chinese standards, compression tests are carried out, as shown in Figure 5 and Table 2. The elastic modulus (Ec) is $3.16 \times 10^{4} \mathrm{MPa}$.

\section{Test Monitoring and Analysis}

\subsection{Test Monitoring Program}

3.1.1. Displacement Monitoring. Vault and convergency displacement are monitored in the test. The settlement value is tested with a level, and the convergency values are tested with a convergence device.

3.1.2. Strain Monitoring. It is shown in Figure 6 that the resistance strain gauge and fiber are set only on one side of the specimen for symmetry. Measuring point arrangement can be divided into the vault area $(\mathrm{Cl}, \mathrm{A} 1$, and $\mathrm{S} 1)$, the largest corner area $(\mathrm{C} 2, \mathrm{~S} 2)$, the top of the straight wall area $(\mathrm{S} 3, \mathrm{~B} 1)$, the straight wall area (A2), and the connection area (from D1 to D4), in which S1 S3 are fiber grating measuring points.

3.1.3. Pressure Monitoring. As what is shown in Figures 7 and 8 , three pressure gauges (Y1 Y3) are set between CTST

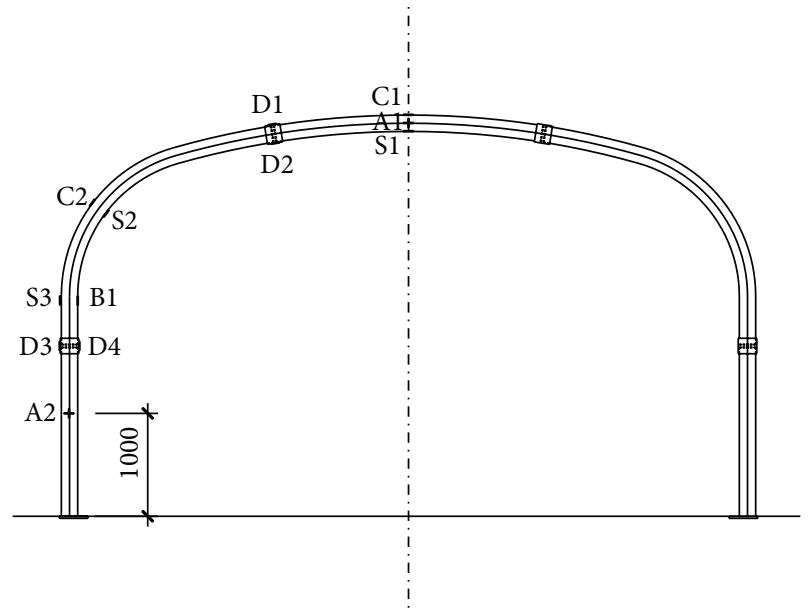

FIGURE 6: The location of resistance strain gauge and fiber.

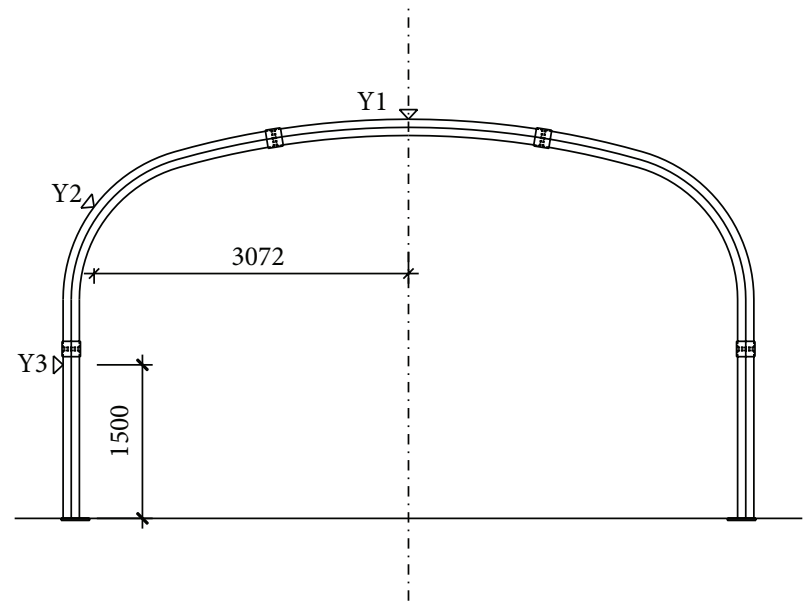

FIGURE 7: The location of pressure gauge.

support (or the steel grid support) and surrounding rock. The pressure gauges are tied to the designed position on the outside surface of the support in site.

\subsection{Test Results Analysis}

3.2.1. Displacement Monitoring Results Analysis. The settlement-time curves in the vaults and convergency value-time curves in both sides are shown in Figures 9 and 10. It is observed that the biggest settlement in the vaults of CTST with concrete is less than $5 \mathrm{~mm}$, while for the one without concrete, it is less than $7.5 \mathrm{~mm}$. The steel grid's biggest settlement in the vaults is less than $7 \mathrm{~mm}$. All the convergency values in both sides of the supports are less than $1.8 \mathrm{~mm}$. The vertical and horizontal deformations of the tunnel are stable after 10 days, so the unobvious deformations in the latter are not shown in Figure 9.

Figures 11 and 12 present load-settlement curves in the vaults and load-convergency value curves in both sides.

It is shown in Figure 11 that the curves of ST-1 ST-3 appeared under the concave due to connection scalability and 


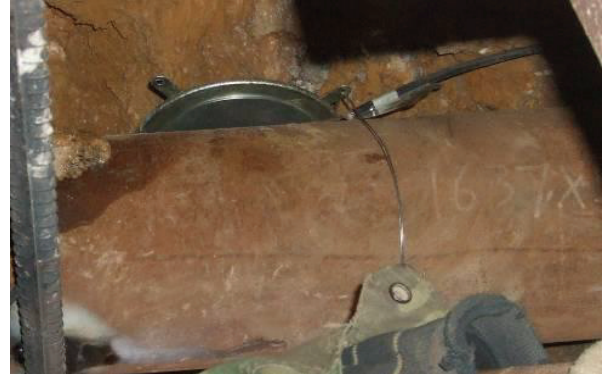

(a) The colligation of the pressure monitor

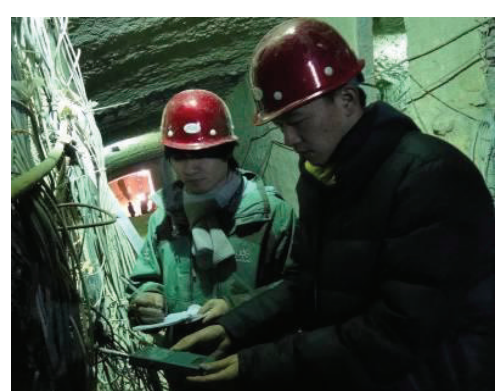

(b) Read the pressure monitor in situ

FIgURe 8: Pressure measurement in situ.

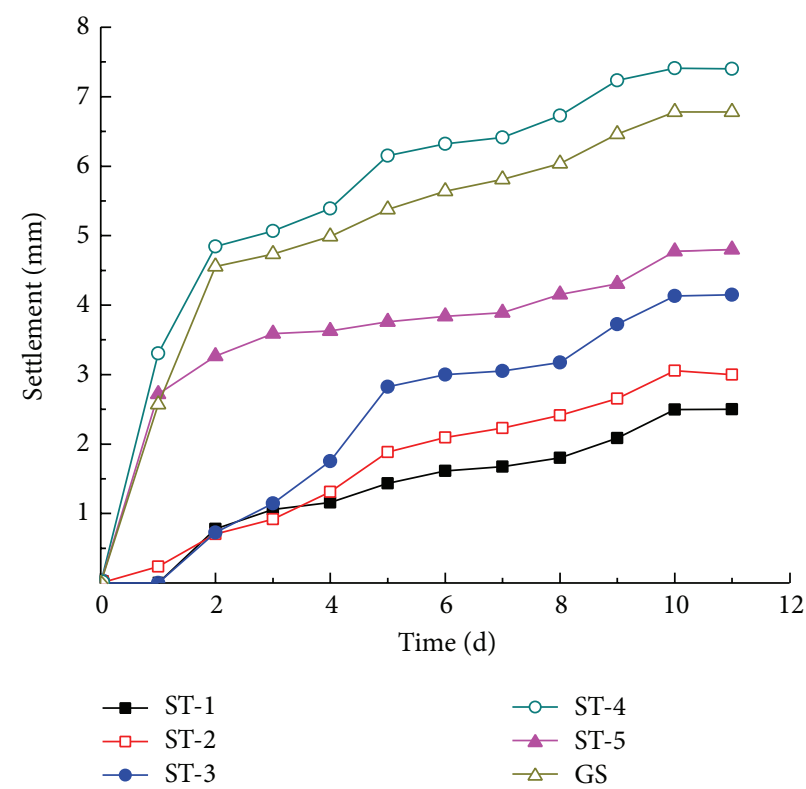

FIGURE 9: Settlement-time curves in the vaults.

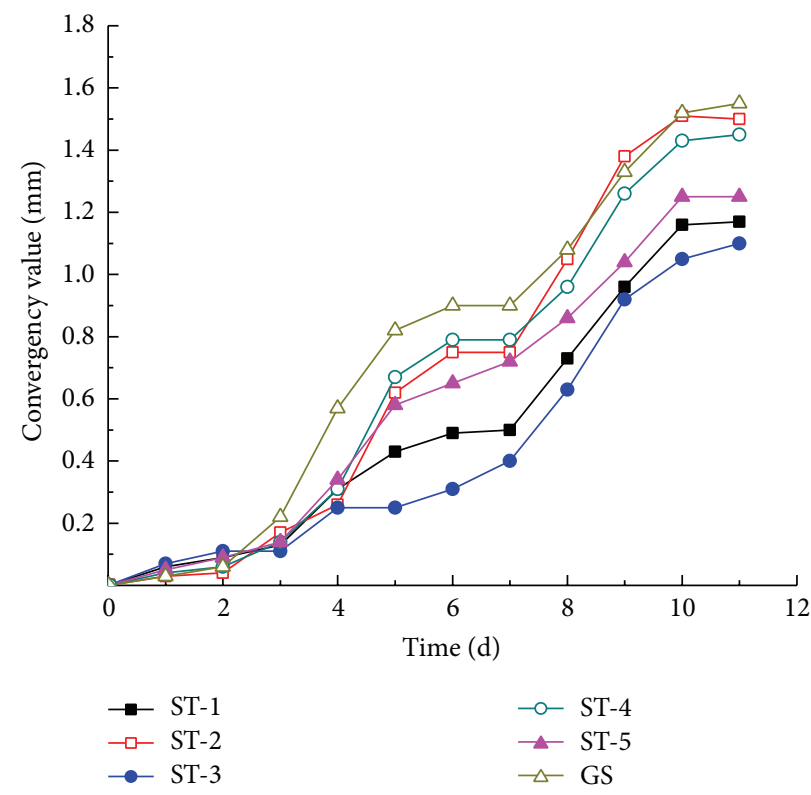

FIGURE 10: Convergency value-time curves in both sides. 


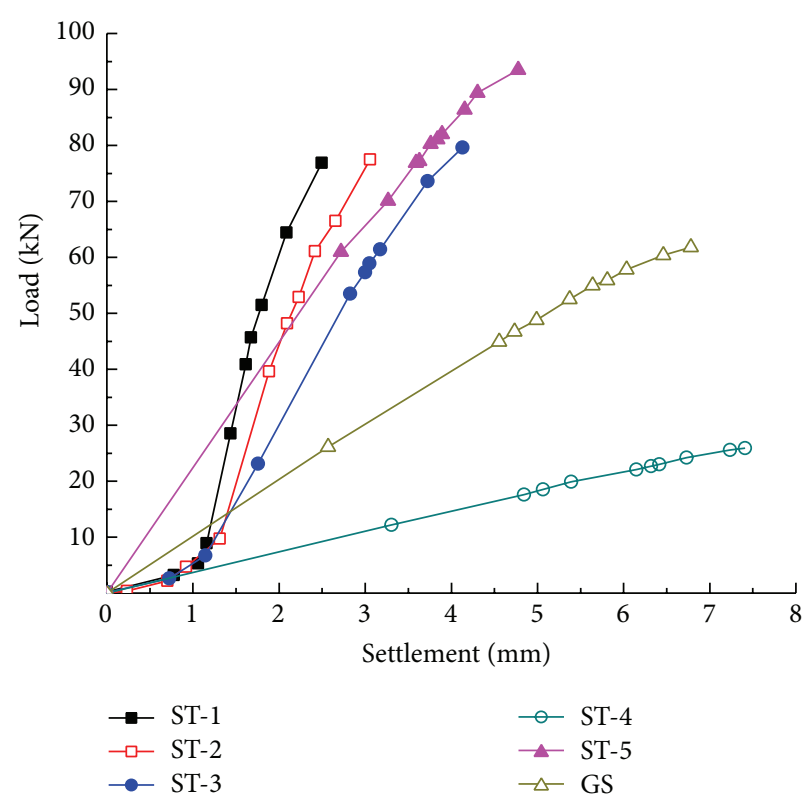

FIGURE 11: Load-settlement curves in the vaults.

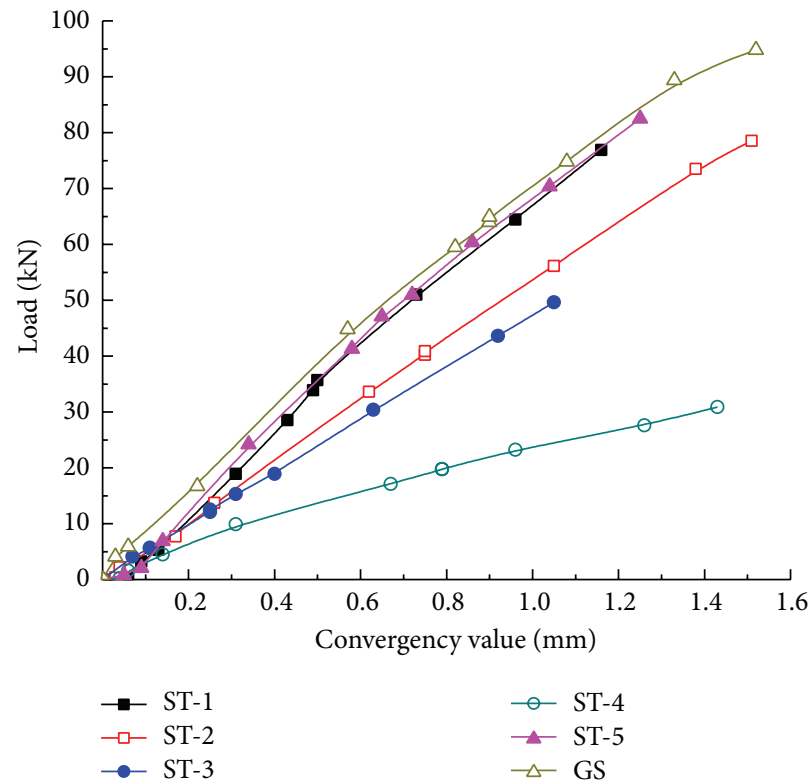

FIGURE 12: Load-convergency value curves in both sides.

smaller gap between surrounding rock and support when the load is less than $10 \mathrm{kN}$. In the later elastic stage, the largest vertical deformation is $2.5 \sim 4.5 \mathrm{~mm}$. The curve of ST- 4 with new connection has no obvious concave. It may be because of the faster deformation and the shorter time of connection compression and gap pressure for CTST without concrete. The curves of ST-5 with common connection and steel grid did not appear under the concave. It can be seen that the main cause of the concave is connection scalability. The straight line slope of ST-1 is bigger than that of ST-5, which presents that the new connection has better resistance to deformation. From the gradually decreasing straight line slopes of ST$1 \sim$ ST-3, it could be concluded that the vertical deformation decreased as the steel thickness enlarged.

It is indicated in Figure 12 that the horizontal deformation of steel grid is less than what happened in CTST under the same load. It might be that the bottom of steel grid is linked to counter-arch, making horizontal stiffness of the support increase. Meanwhile, the higher steel ratio and concrete inside the support would lead to larger stiffness. 


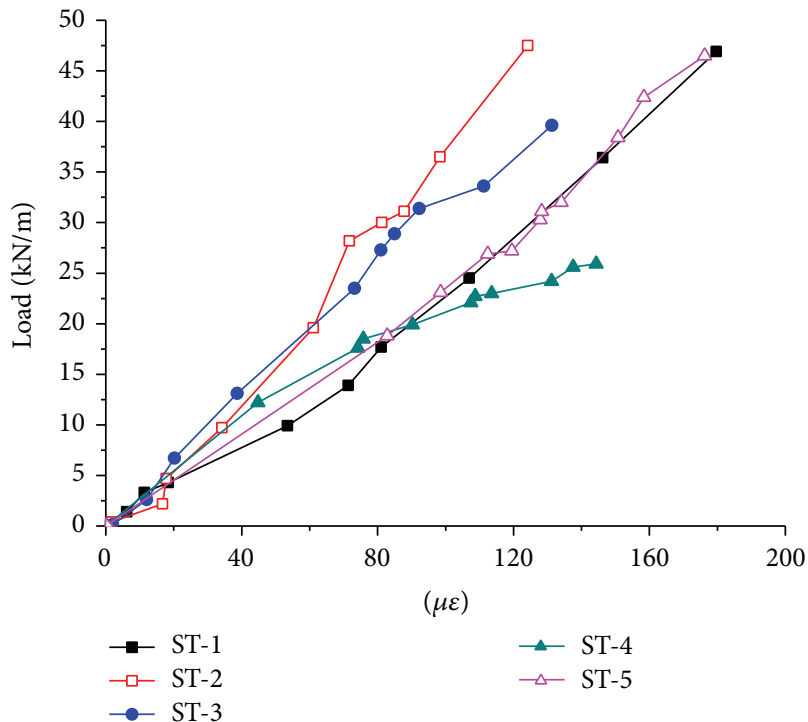

(a) $\mathrm{Cl}$

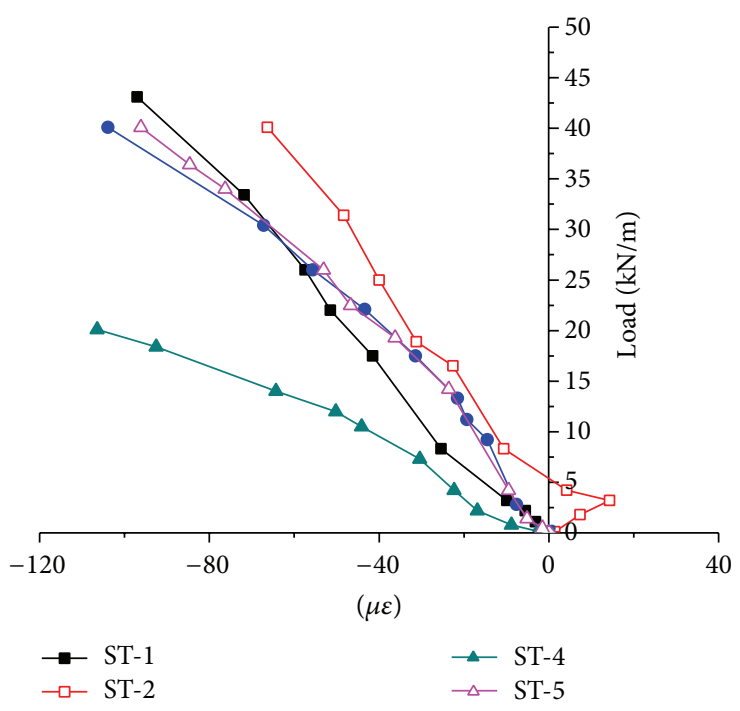

(b) $\mathrm{C} 2$

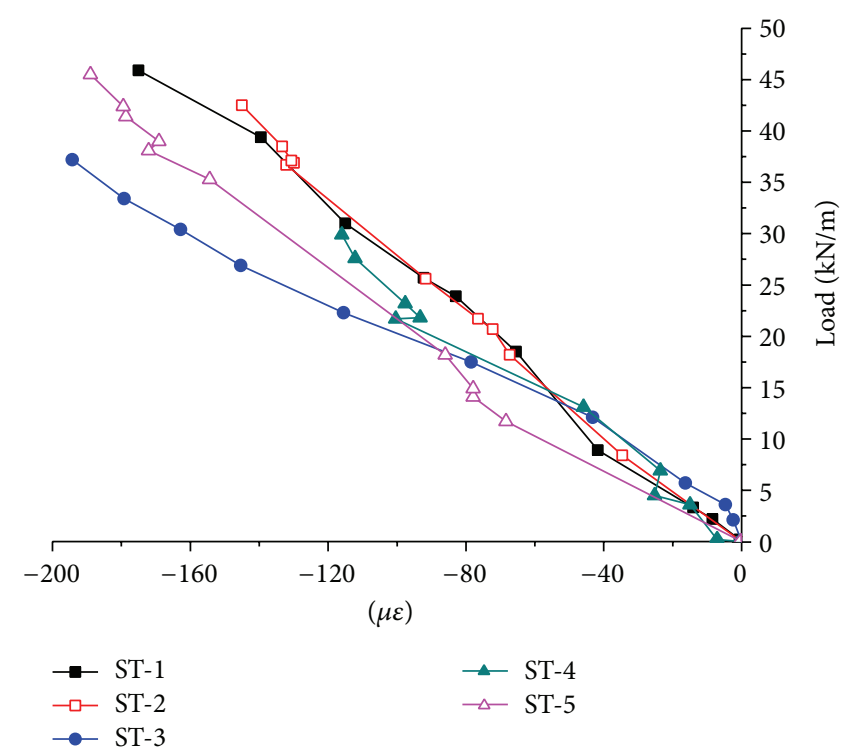

(c) $\mathrm{S} 3$

FIGURE 13: Load-strain curves in the outer edge of the CTST supports.

3.2.2. Strain Monitoring Results Analysis. In this study, tangential strains of 5 CTST supports are mainly monitored.

(1) Strain Curves of the Outer Edge. It is indicated in Figure 13 that each curve in addition to C2 in the ST-2 support is almost a straight line, which suggests that the specimen performed linear elastic as a whole. The slope of ST-2 in the largest corner changes from positive to negative. It may be caused by steel tube defect or the local stress concentration by concrete inside filling the gap. The support vault of the outer edge (C1) is in the tensile force. While both the largest corner (C2) and the top of the straight wall (S3) are in the compressive force, the absolute values of maximum tensile and compressive strains are less than $200 \mu \varepsilon$. Each strain of ST-4 is bigger than ST-3 which means that the steel tube with concrete filling could effectively improve the ability of resisting deformation.

(2) Strain Curves of the Center Axis. It is described in Figure 14 that both the vault (A1) and the straight wall (A2) are in the compressive force with the absolute strain values less than $200 \mu \varepsilon$. Each load-strain curve is almost a straight line.

(3) Strain Curves of the Inner Edge. It could be seen in Figure 15 that each load-strain curve of the inner edge of CTST supports is also almost a straight line. The vault (S1), the largest corner (S2), and the top of the straight wall (B1) are in 


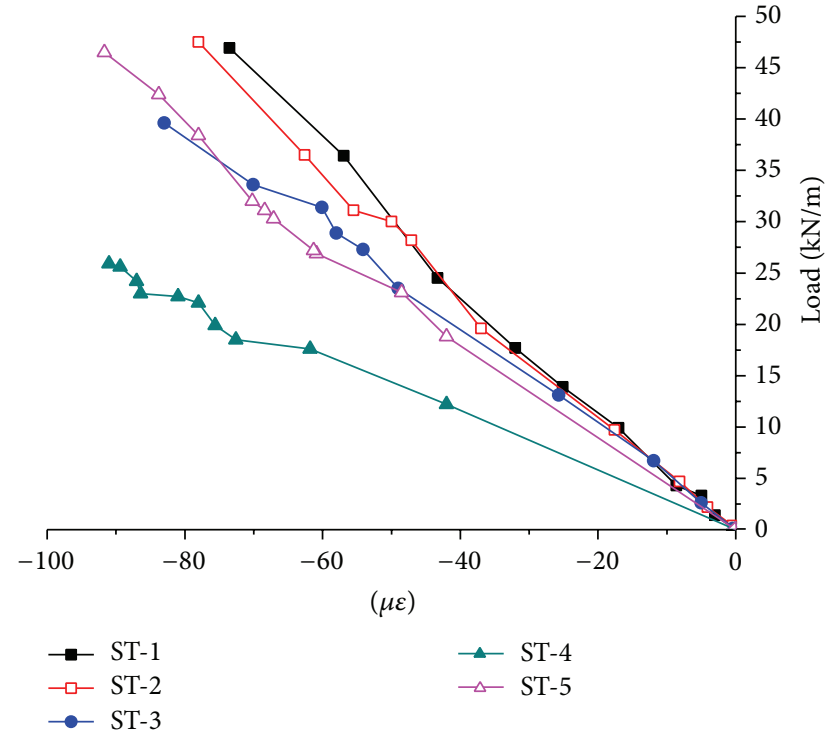

(a) $\mathrm{Al}$

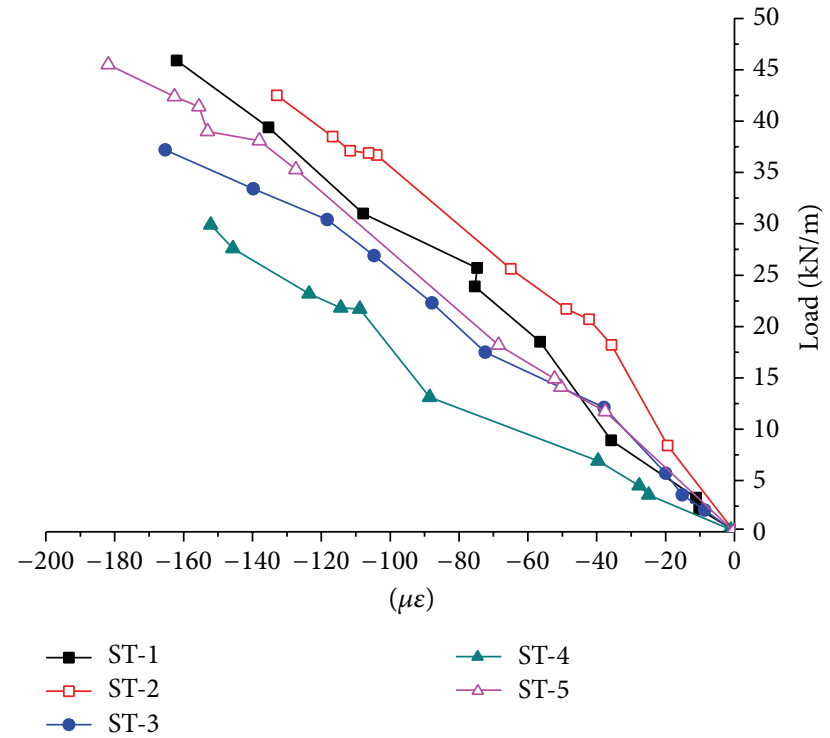

(b) A2

FIGURE 14: Load-strain curves on the center axis of the CTST supports.

the compressive force with the absolute strain values less than $275 \mu \varepsilon$. The specimens performed elastic. The steel thickness and the style of connection cannot influence the load-strain curve in the inner edge obviously.

(4) Strain Curves of the Connections. As displayed in Figure 16, load-strain curves in the inner edge of the CTST supports have obvious properties. The curves of supports with cementitious grouted sleeve (ST-1 ST-4) can be roughly divided into flat part and growing part. Early strain grows faster than the load, which means that the cementitious grouted sleeve connection exhibits superior flexibility. The curve of support with common sleeve (ST-5) has no obvious flat part, reflecting its connection with bigger stiffness. All the absolute values of maximum tensile and compressive strains at the connections are less than $250 \mu \varepsilon$.

(5) Strain Distribution Curves of the Inner and Outer Edges. Owing to symmetry of CTST supports, the strain distribution curves are tested only on the left side of the support. The maximum strain distributions of the inner and outer edge of the supports are shown in Figures 17 and 18.

It is obvious that the tensile strain was gradually transformed into compressive strain along the direction of vault to the straight wall in the outer edge. All the straight walls are in compression. The maximum tensile strain of outer edge is located in the vaults while the maximum compressive strain is generated near the lower connection. The inner edges of the CTST supports are all in compression with the maximum strain in the vaults. But the maximum compressive strain of ST-5 is located near the lower connection. The compressive strain values of vault, foot, and area near the lower connection are relatively larger.

\section{Numerical Analysis}

4.1. The Finite Element Modeling. The finite element analysis (FEA) of ST-1 ST-3 by ABAQUS program is conducted. Four-noded shell element with reduced integration (S4R) is used for steel tube. Von-Mises kinematic hardening rule is adopted for steel material. The elasticity modulus of steel takes $206 \mathrm{GPa}$. Poisson's ratio takes 0.30 .

The three-dimensional 8-noded solid element with reduced integration (C3D8R) is used to mesh the concrete. The elasticity modulus takes $4730 \sqrt{f_{c}^{\prime}}, f_{c}^{\prime}$ mean compression cylindrical strength of concrete. Poisson's ratio takes 0.20. The interface behavior in the tangential direction employs the Coulomb friction model.

Considering the influences of surrounding rocks at the scope of 5 times the width, the spacing of support $(0.5 \mathrm{~m})$ was taken as the width of surrounding rock. Considering that the mid-separate wall was established between CTST supports in the experiment which could affect the force situation, a vertical constraint was added at both sides in the outer edges of the concrete lining. Only $1 / 2$ model is needed when calculation according to the structure symmetry, as shown in Figure 19.

In this test, the displacement values were taken as the load to apply to the supports, and the FEA results were compared with the testing results.

4.2. FEA Results and Contrastive Analysis. Based on the FEM results, the maximum strain distribution curves of the inner and outer edge of ST-1 ST-3 are shown in Figures 20 and 21. Table 3 describes the comparison of the maximal strain between FEA and test results. 


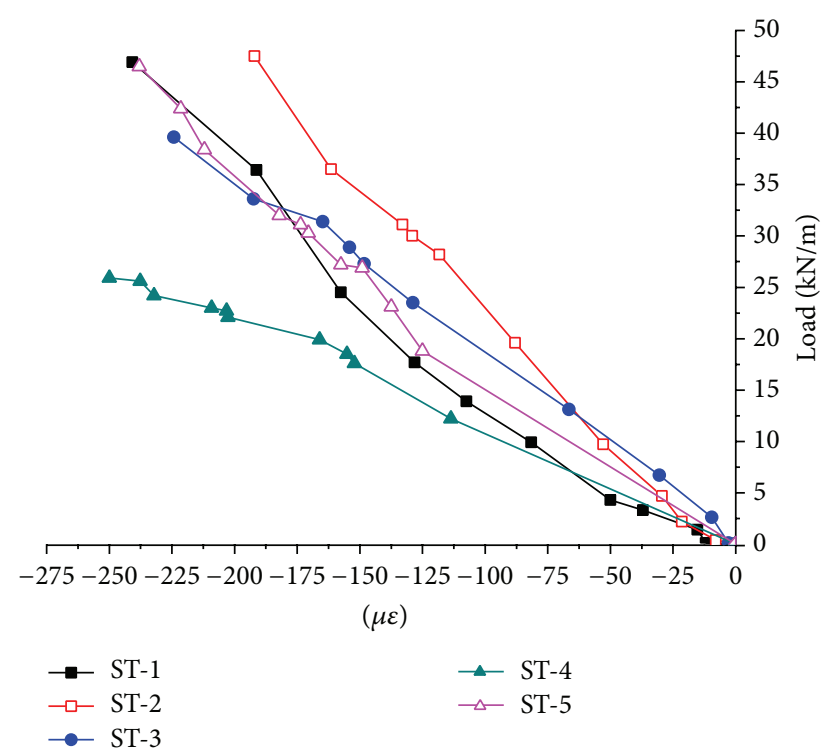

(a) $\mathrm{S} 1$

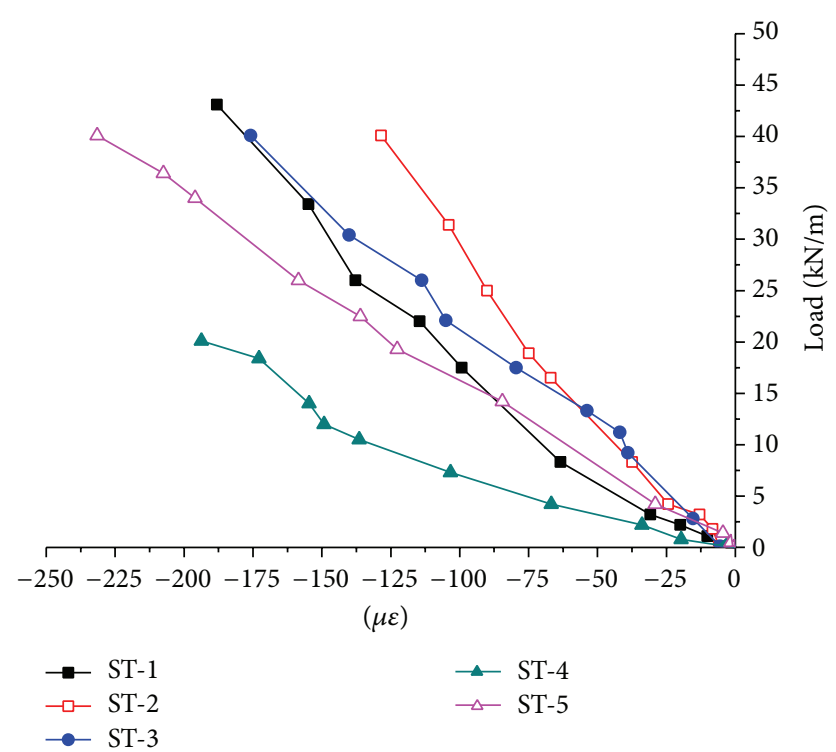

(b) S2

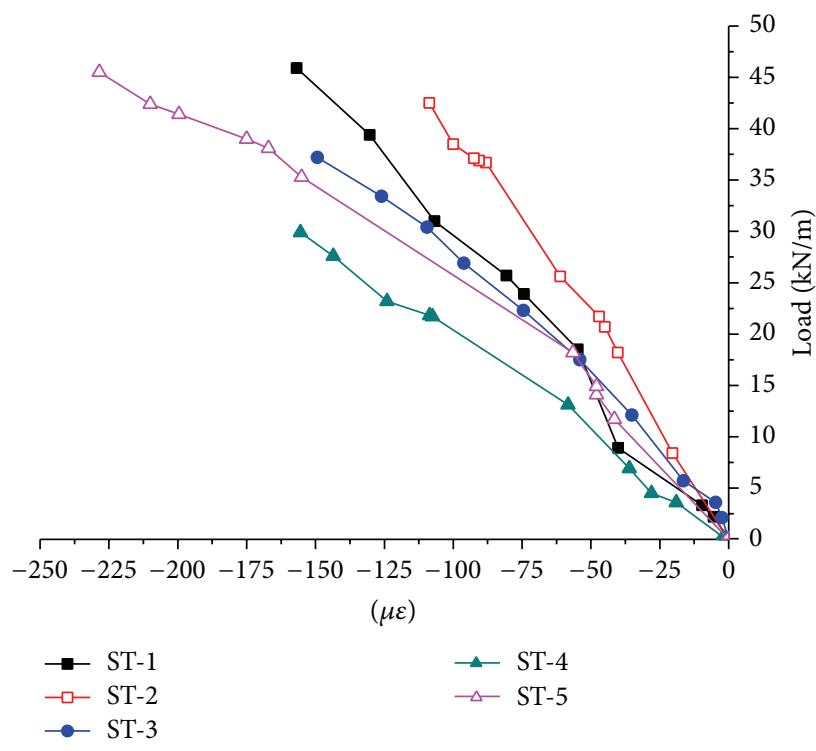

(c) $\mathrm{B} 1$

FIGURE 15: Load-strain curves in the inner edge of the CTST supports.

From Table 3, it is observed that the maximum strain distribution curves of the FEA results are in good agreement with the experimental results. The average error rate of each measuring point (vault, largest corner, top of the straight wall, and foot) in the outer edge is $6.4 \%, 7.1 \%, 5.5 \%$, and $7.2 \%$, respectively. The average error rate of each measuring point (vault, largest corner, top of the straight wall, and foot) in the inner edge is $6.0 \%, 3.0 \%, 6.2 \%$, and $6.1 \%$, respectively. The maximum error of all measuring points is $10.2 \%$. It may be caused by less number of horizontal and vertical measuring points, as a result of some differences between the displacement load applied on the model and the real displacement. Comparing with the experimental data, it is observed that the FEM adopted in this section is reasonable, which can be well simulated with the working condition of CTST supports in tunnel and can be used for the structural analysis of the similar projects.

\section{Conclusions}

In line with the results of the experimental study and FEA analysis, the results could be summarized as follows:

(1) With better compression resistance, CTST benefits to resist against the deformation of the tunnel. The deformation of tunnels with CTST can reach the steady state in a short time. 


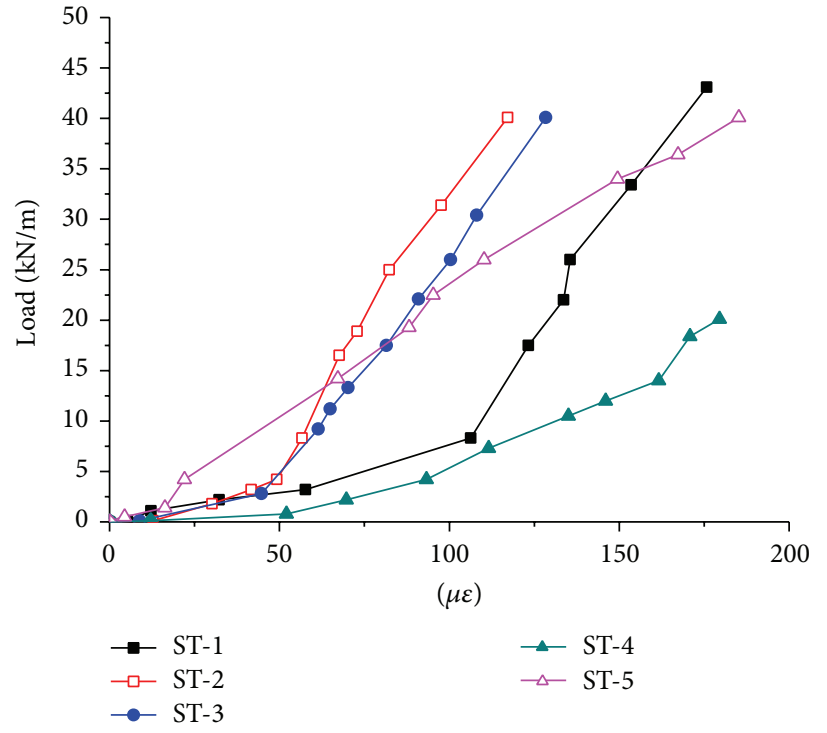

(a) D1

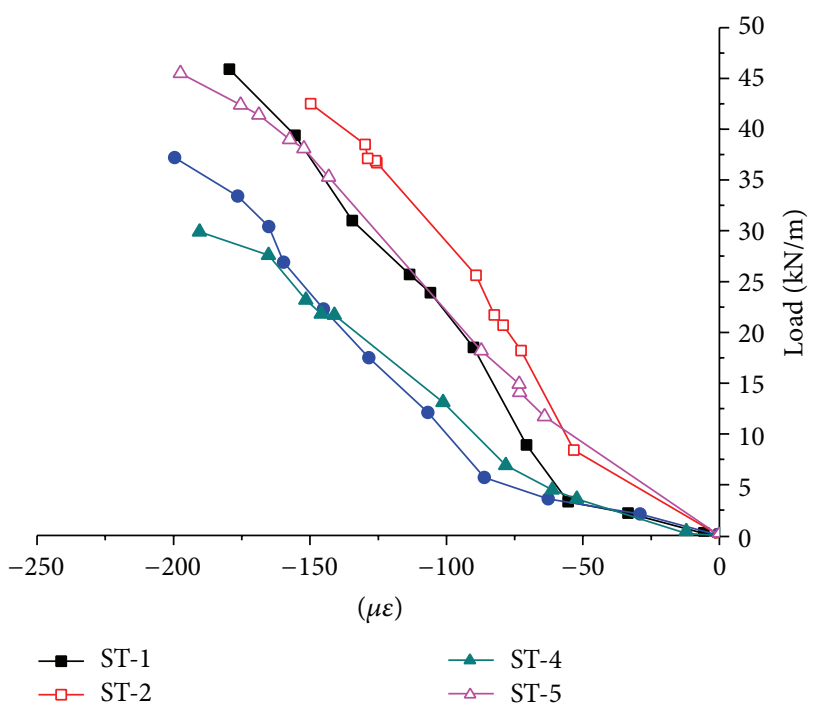

(c) D3

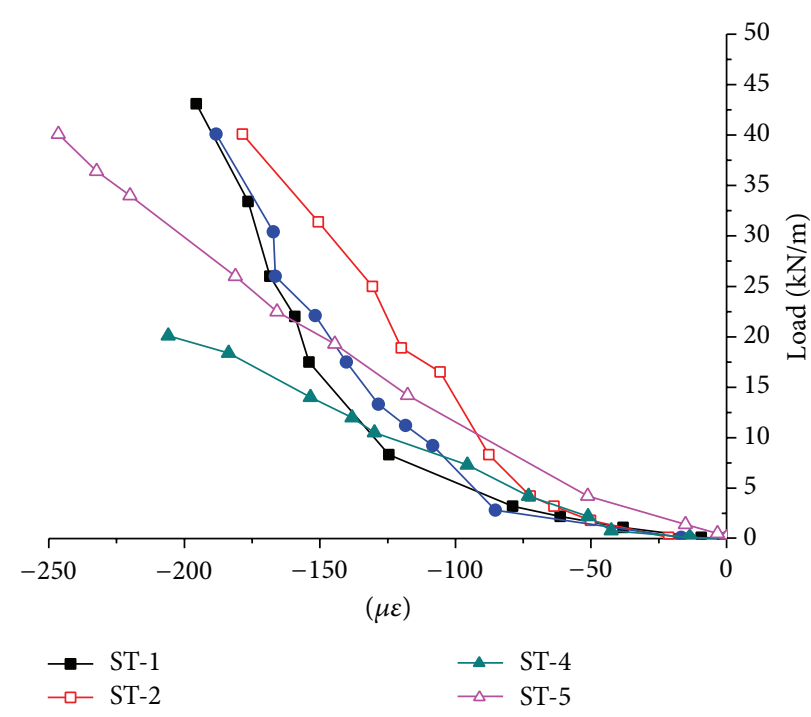

(b) $\mathrm{D} 2$

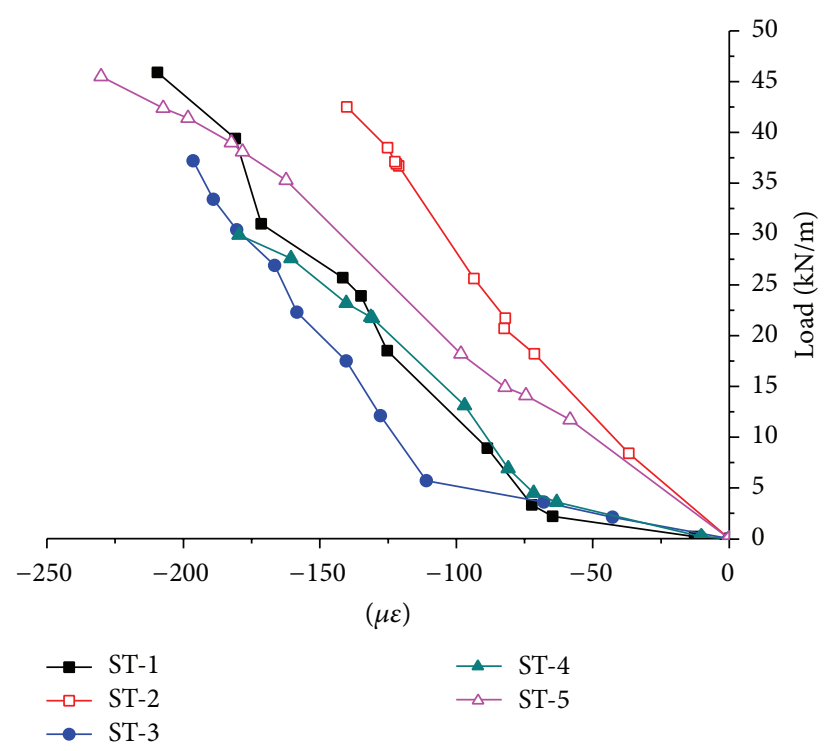

(d) $\mathrm{D} 4$

FIGURE 16: Load-strain curves at the connections of the CTST supports.

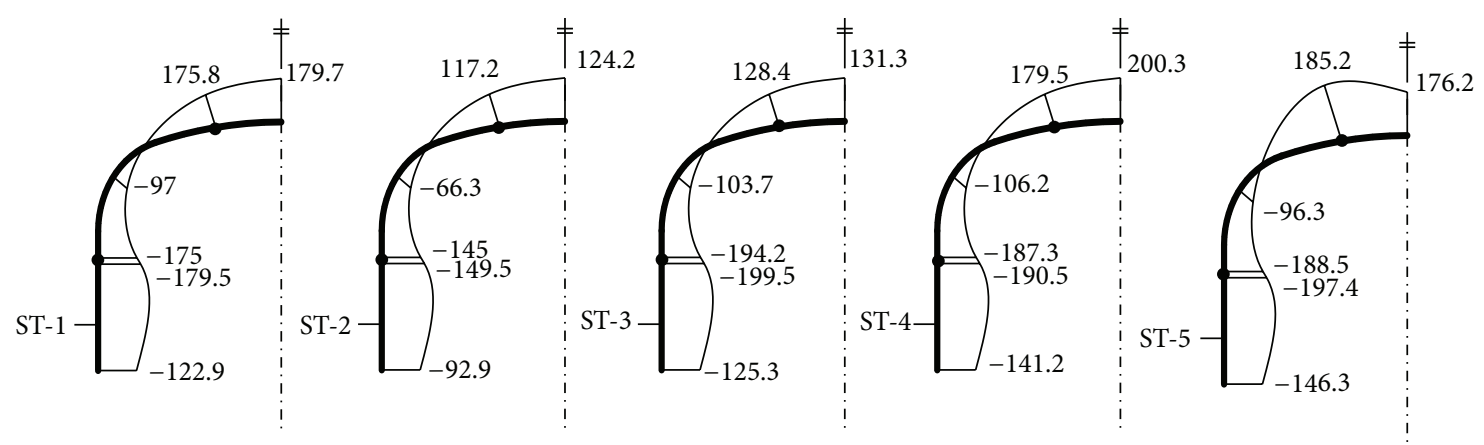

FIGURE 17: Strain distribution curves in the outer edge of the CTST supports. 

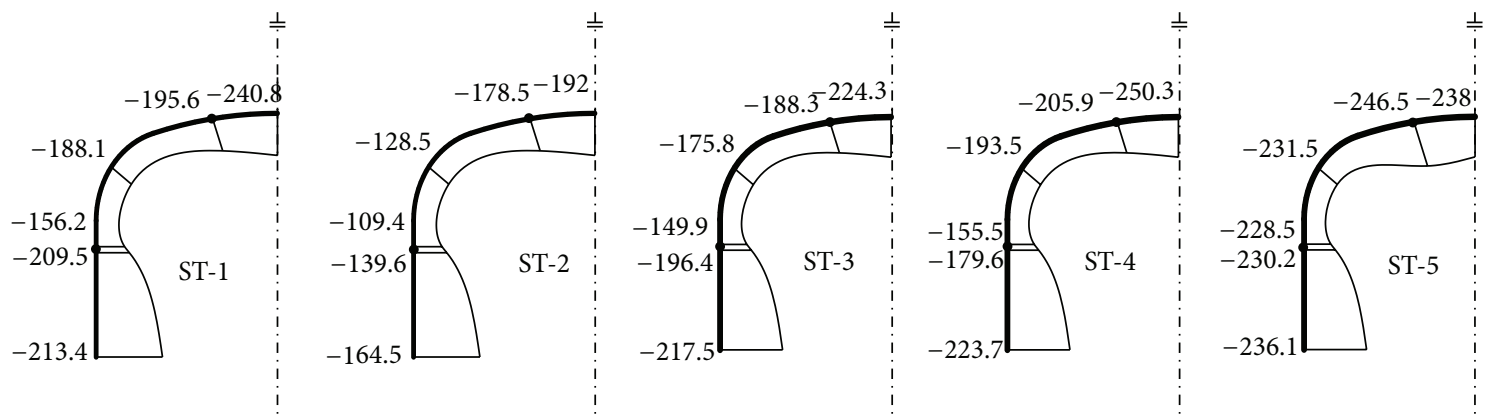

FIGURE 18: Strain distribution curves in the inner edge of the CTST supports.
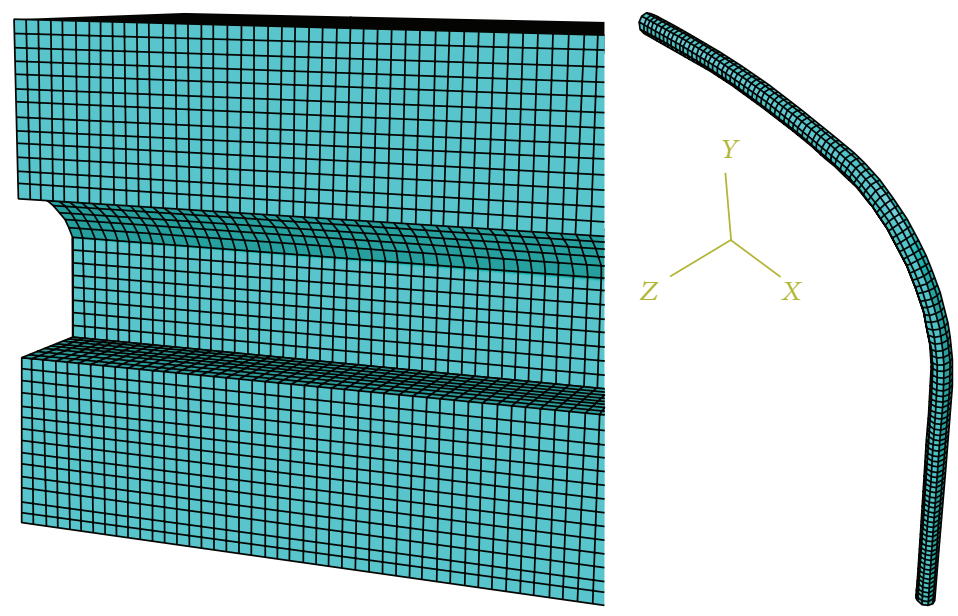

(a) The whole mesh of tunnel

(b) Lining and support mesh

FIgURE 19: Mesh of steel tube model.

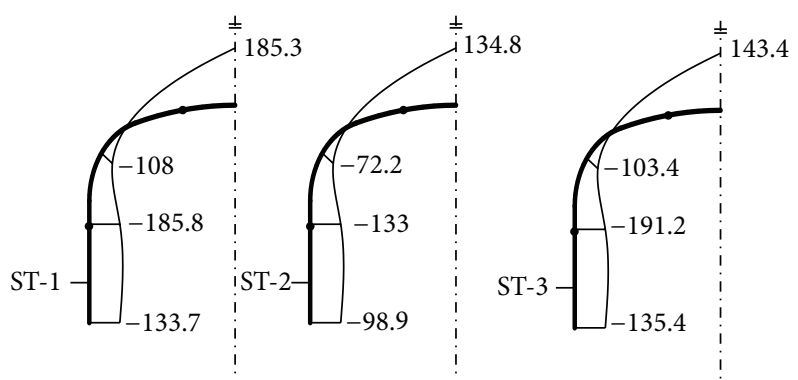

FIGURE 20: Strain distribution curves in the outer edge of the CTST supports.

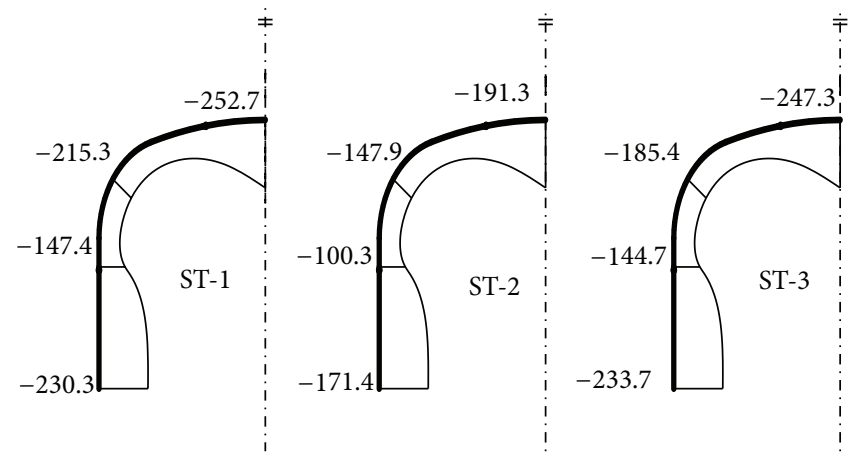

FIGURE 21: Strain distribution curves in the inner edge of the CTST supports. 


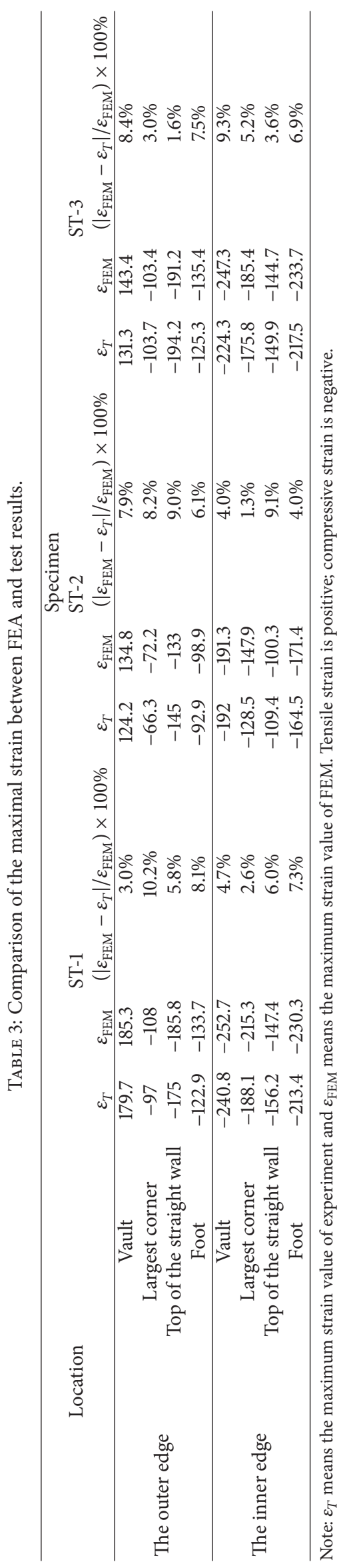


(2) All of the CTST supports perform elastic during the experiment. The higher steel ratio and concrete inside, the larger stiffness of CTST obtained.

(3) The cementitious grouted sleeve connection with superior flexibility exhibits better resistance to deformation.

(4) The tensile strain is gradually transformed into compressive strain along the direction of vault to the foot in the outer edge. The inner edges of the CTST supports are all in compression. The absolute strain values of vault, connections, and tube foot are larger.

(5) The mechanical behaviors of CTST supports in the tunnel are analyzed with ABAQUS software package. The analysis results agree well with the test results. The maximum error is $10.2 \%$. The model and the parameters chosen are relatively reasonable and could be used for the structural analysis of the similar supporting projects.

\section{Conflict of Interests}

The authors declare that they have no conflict of interests.

\section{References}

[1] M. Elchalakani and X.-L. Zhao, "Concrete-filled cold-formed circular steel tubes subjected to variable amplitude cyclic pure bending," Engineering Structures, vol. 30, no. 2, pp. 287-299, 2008.

[2] M. V. Chitawadagi and M. C. Narasimhan, "Strength deformation behaviour of circular concrete filled steel tubes subjected to pure bending," Journal of Constructional Steel Research, vol. 65, no. 8-9, pp. 1836-1845, 2009.

[3] Y.-F. An, C. Roeder, and L.-H. Han, "Flexural performance of concrete-encased concrete-filled steel tubes," Magazine of Concrete Research, vol. 66, no. 5-6, pp. 249-267, 2014.

[4] L.-H. Han, S.-H. He, and F.-Y. Liao, "Performance and calculations of concrete filled steel tubes (CFST) under axial tension," Journal of Constructional Steel Research, vol. 67, no. 11, pp. 16991709, 2011.

[5] W. Li, Q. Wang, D. Wang et al., "Experimental study on short columns under axial load of U-type confined concrete arch centering and its application in mine," Journal of Mining \& Safety Engineering, vol. 31, no. 1, pp. 1-9, 2014 (Chinese).

[6] A.-Y. Jiang, J. Chen, and W.-L. Jin, "Experimental investigation and design of thin-walled concrete-filled steel tubes subject to bending," Thin-Walled Structures, vol. 63, pp. 44-50, 2013.

[7] B. Uy, "Strength of concrete filled steel box columns incorporating local buckling," Journal of Structural Engineering, vol. 126, no. 3, pp. 341-352, 2000.

[8] M. Mursi and B. Uy, "Strength of concrete filled steel box columns incorporating interaction buckling," Journal of Structural Engineering, vol. 129, no. 5, pp. 626-639, 2003. 

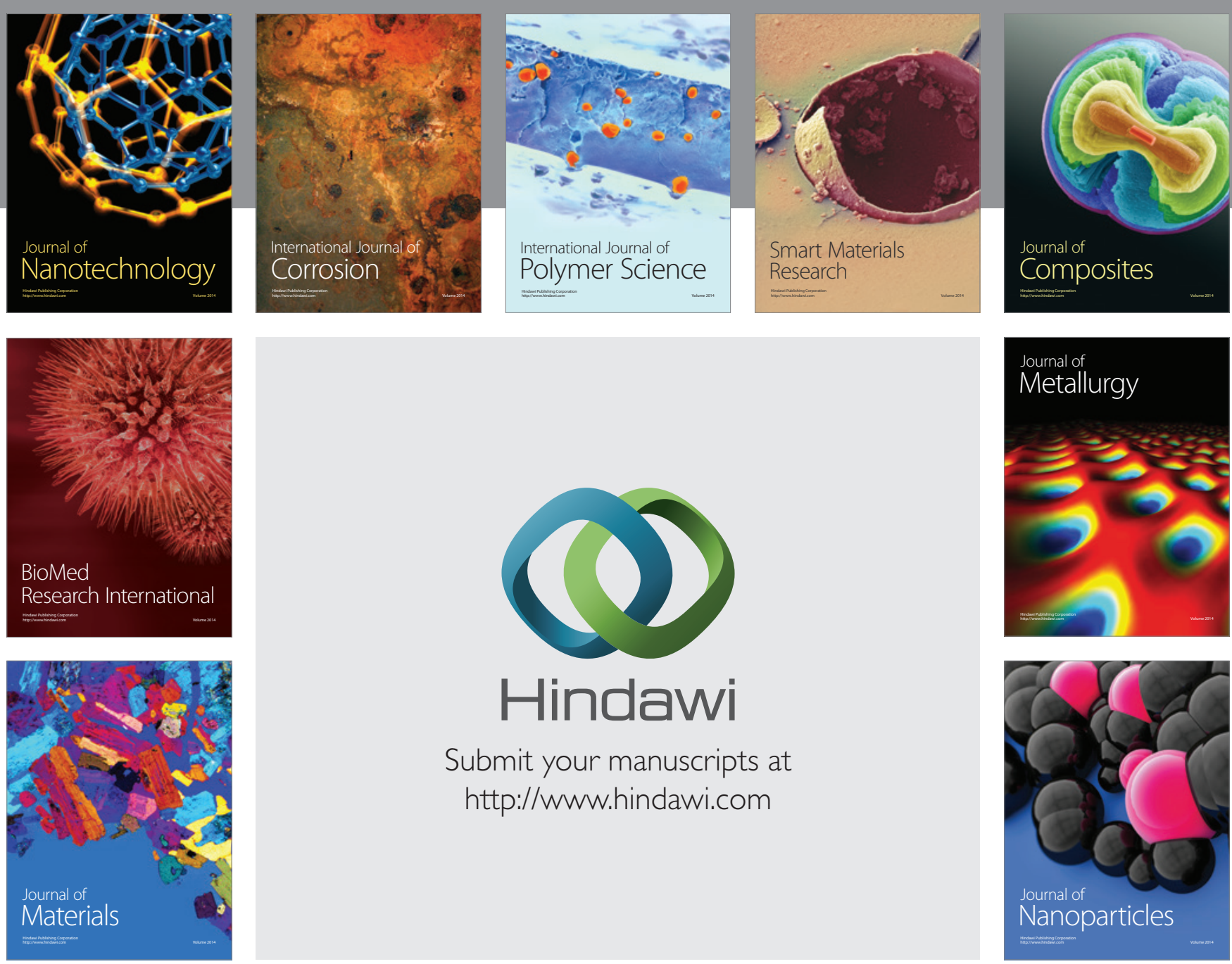

Submit your manuscripts at http://www.hindawi.com
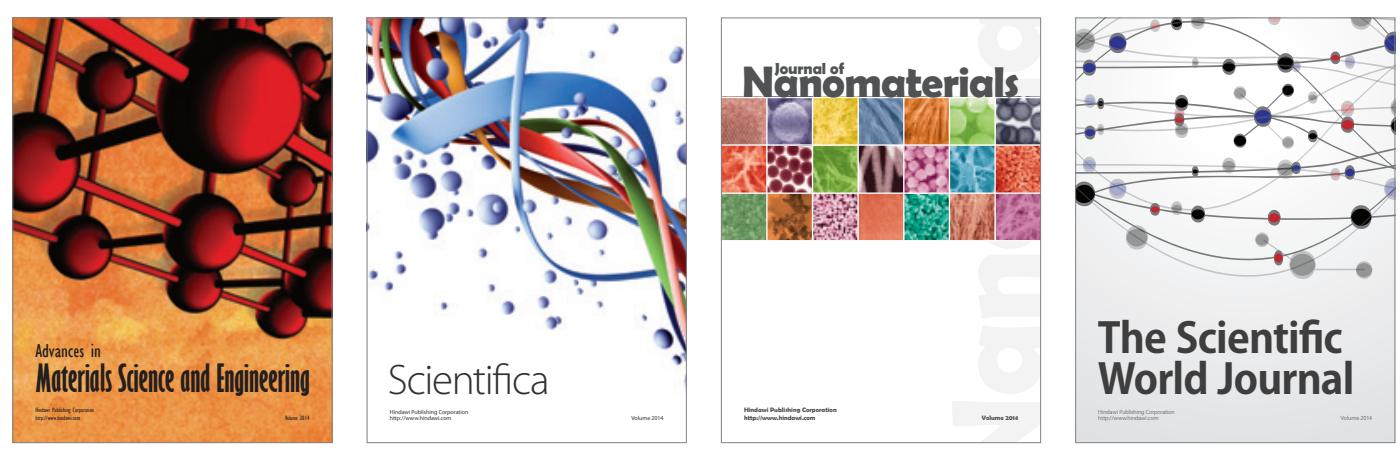

\section{The Scientific World Journal}
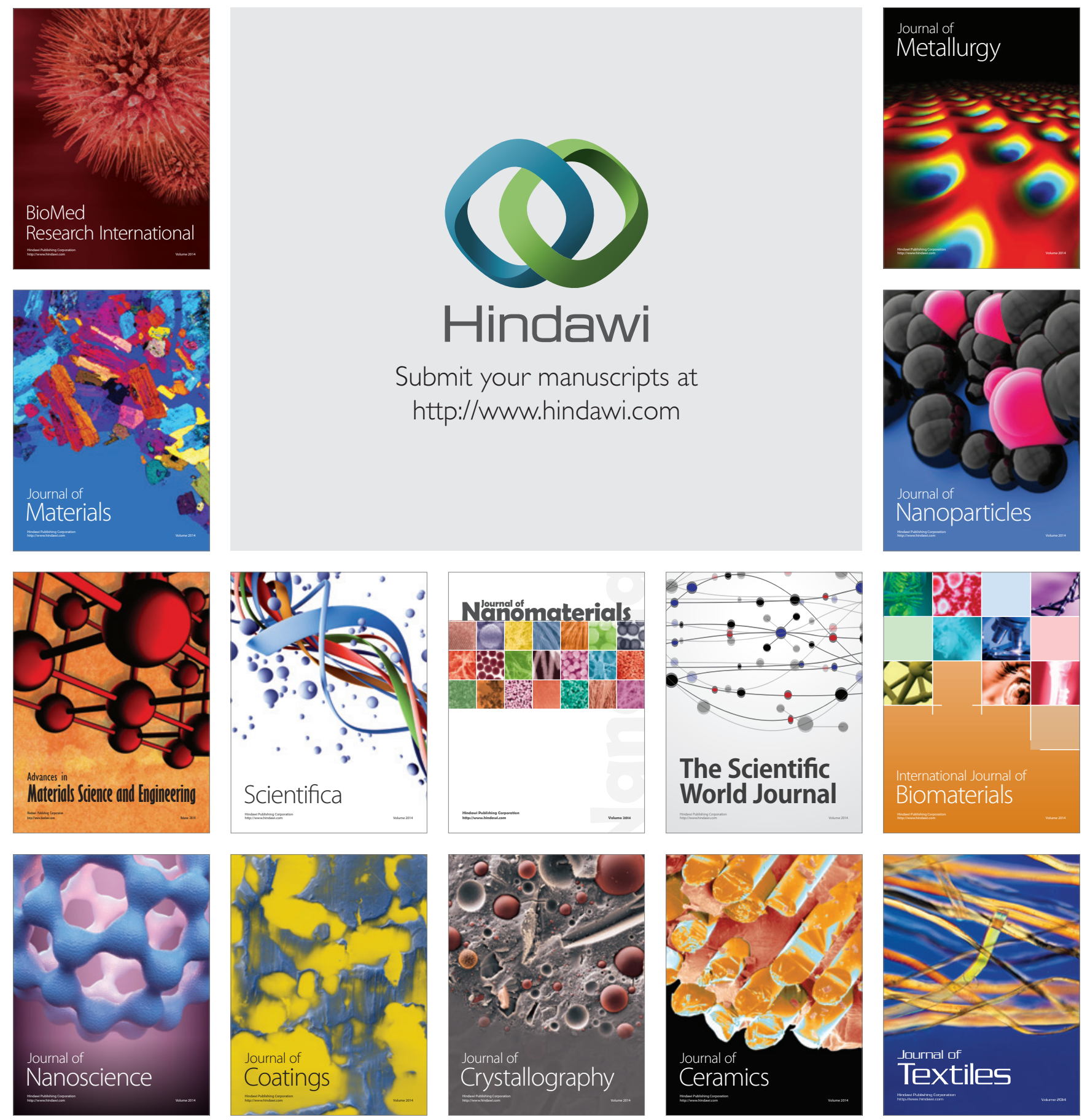